\title{
A Framework for Selection of Information Systems Development Methodologies
}

\author{
Masoud Yaghini \\ Department of Railway Engineering, Iran University of Science and Technology (IUST) \\ Narmak, PO box 1684613114, Tehran, Iran \\ Tel: 98-21-7749-1238 E-mail: yaghini@iust.ac.ir \\ Atieh Bourouni (Corresponding author) \\ Department of Industrial Engineering, Iran University of Science and Technology (IUST) \\ Narmak, PO box 1684613114, Tehran, Iran \\ Tel: 98-912-5007-402Ｅ-mail: bourouni@ind.iust.ac.ir \\ Roozbeh Hesam Amiri \\ Department of Industrial Engineering, Iran University of Science and Technology (IUST) \\ Narmak, PO box 1684613114, Tehran, Iran \\ Tel: 98-912-5356-487_E-mail: amiri_r@ind.iust.ac.ir
}

\begin{abstract}
Information systems are increasingly becoming regarded as crucial to an organisation's success. A development methodology for an information system is a framework to organize, program and supervise the process of developing an information system. There many are different methodologies for information systems development. Obviously, no methodology can claim that it can be applied to any organisation. Therefore, organisations should have an evaluation framework for selecting an appropriate and efficient methodology. In this paper, we propose an evaluation framework for selecting information systems development methodology in order to facilitate the development process of information systems in organisations.

In this work, we will describe and compare different hard and soft systems approaches at first, then in the following sections, one kind of methodology's classifications is pointed and one methodology from each class is introduced. Finally, a comparison framework is proposed and methodologies are compared by this framework. The value of this framework is that, with use of it, organisations can evaluate their development methodology with respect to the key features of it before implementing any methodology as well as expending extra costs. This framework is theoretical in nature, and is build based on a review of related literature.
\end{abstract}

Keywords: Systems methodologies, Information systems, Methodology selection, Methodology comparison framework

\section{Introduction}

Methodology is defined by Britain computer society (BCS): (Avison, 2006)

"Systems development methodology is a set of recommended means for information systems development or part of it which is based on logics and specific philosophy. The recommended means often contain of definition of phases, procedures, activities, rules, techniques, documentations, tools and guidance. It may also include suggestions which notice on management and organisation, approach and determining and training participations.”

In last decades, it is clear for anyone that information systems and their development are important. Information systems development is a complicated and long process in which different elements collaborate from beginning to end. It is evident that programming and managing these projects are very hard and even impossible without utilizing a methodology (Inman, 2006). Many researchers and companies have designed and introduced methodologies in academic and commercial levels. Each of these methodologies uses a set of tools, models, and specific concepts; therefore they are successful and applicable in some specific backgrounds. Whereas these methodologies are very 
numerous, selecting appropriate methodology for applying in a specific system is a very important and difficult process. Two different approaches can generally be adopted in the process of this methodology selection: (Niaki, 2001)

Select a known methodology and accomplish its steps carefully;

Combine two or many comparatively suitable methodology and adjust them according to specific situation of project.

Methodology comparison is done with the following purposes: (Avison, 2006)

Academic purpose: for better understanding the nature of methodologies (goals, philosophy, characteristics and so on.) in order to do some classifications and improving coming information systems development

Practical purpose: to select one or more methodologies for specific applications or the whole organisation.

In this paper, at first, hard and soft systems approaches are considered and compared, then one kind of methodology's classifications is pointed and one methodology from each class is introduced. At the end, comparison frameworks were proposed and methodologies are compared by this framework.

\section{Hard and Soft Systems Approaches}

Hard systems thinkers observe the world systematically. They believe that systems have a specific and defined goal and determined boundary. In other words, there is no search about system's goal and boundary. Hard systems analysis in mechanical cases or simple biophysical problems would be useful. Hard systems thinkers observe social phenomena as stable, predictable, and repeatable problems.

On the other hand, soft systems thinkers believe that problems are happening when hard systems thinking is applied in problem situations which in behavior, action, and human aspects are effective factors. They know phenomena as dynamic, unpredictable, full of chaos, and immethodical. They do not always observe the world systematically but sometimes observing the world systematically is known useful. (Checkland, 1981)

In order to distinguishing that the information systems development problem is hard or soft, a framework which is represented by Harry is used (Harry. 1997):

Definition: Is there any knowing and agreeing about what the problem is?

Boundary: Does the definition of problem enable the clarification of what the problem is, and what it is not?

Separation: Can issues be dismissed as being not part of the problem as a result of drawing the boundary?

Responsibility: Does the definition and separation of the problem make it clear who should be involved in its solution and who not?

Information: If there is clarity on what the problem is and whose responsibility it is, do we know what information is required for its solution?

Description: Is it known what a solution would, and would not, look like if all the previous criteria have been satisfied?

If the answer to these questions based on all the above criteria is "yes", then the problem can be classified as a hard problem. If at least one of these answers is "no", we are facing a soft or hard uncertainty problem.

According to Checkland, the most important difference between the two concepts is the fact that in hard systems thinking, the end result would be to implement the designed system, while in soft systems thinking, one would implement the agreed changes. (Watkins, 2003)

\section{Hard Systems Methodologies in Information Systems Development}

Different classifications are represented for hard methodologies. In this paper, we gain this taxonomy by combining some of them: (Harry, 1997; Scott, 2005; Course of information systems development, 2005)

Structured methodologies

Data-oriented methodologies

Process-oriented methodologies

Blended methodologies

Object-oriented methodologies

In the next chapter, each of these classifications is introduced as well as a methodology of each classification.

\subsection{Data-Oriented Methodologies}

In this group of methodologies, the focus is on the data aspect of system to information systems development and data flows are very important. Information engineering methodology (IEM) is an example of this group.

The basic framework of information engineering methodology is developed by Clive Finkelestien and James Martin. Its 
source is the methods which Finklestien suggested for data modeling in the end of 1970s in Australia. In 1981, they published a book with a title, information engineering, which described principles and its application of methodology. On the other hand, in the end of 1970s, another group in England innovated a new methodology, system development in a shared data environment (D2S2). It is effective on IE methodology development. For the moment, different narratives of these methodologies are represented by numerous companies and organisations which insert on general IE framework but each of them are different to each other according to circumstances or focuses on parts of methodology. Martin said regarding this subject: "It should not consider that IE is a completely specific methodology. Identical software engineering, IE is an echelon of methodologies." (Avison, 2006)

Different steps of IE are as follows: (Course of information systems development, 2005)

1) Information strategic planning which is contained existing situation analysis, needs analysis, architecture definition and information strategic plan collect.

2) Domain analysis which is earning attributes analysis, interaction analysis, existing systems analysis, designing confirmation and planning.

3) Design and programming system:

Logical designing

Technical designing

4) Build and implementation:

Build: producing and evaluating system

Implementation

Protecting

\subsection{Process-Oriented Methodologies}

This group, unlike data-oriented methodologies, focuses on existing processes in information system and tries to apply these processes into information systems development. Yourdon systems method (YSM) is one of these methodologies.

This method is one of the most comprehensive systems development methodologies whose last version is represented in 1993. Yourdon innovated this method in order to eliminate inexpressiveness's which these methods have indicated in practice. This method has three phases which each of them have some steps. Its steps and phases are as follows: (Yourdon Inc., 1993)

Phase 1: Feasibility

Interviewing with users

Building DFD

Building ERD

Phase 2: Main model building

Building Enterprise Essential Model (EEM)

Building System Essential Model (SEM)

Phase 3: Performance model building

Building Enterprise Performance Model

Building System Performance Model

\subsection{Blended Methodologies}

In this group, the attention in information systems development process is on both data and process aspect of the system. The most important methodology in this group is Structured Systems Analysis and Design Methodology (SSADM).

At first, SSADM was represented to standardize development methods and built systems in governmental centers by CCTA in 1981. By now, it has changed very much. On of the results would be technology's changes and methodology week points. Its third edition introduced new techniques to contact users with system in 1986. In version 4.0, prototyping technique was mooted at first time. Its last version, 4.3, was represented in 1996. (Avison, 2006)

This methodology steps are expressed in five phases and seven steps which are as follows: (Poon, 2005)

Phase 1: feasibility study

Stage 0 : feasibility

Phase 2: requirement analysis 
Stage 1: investigation of current environment

Stage 2: business system options (BSO)

Phase 3: requirement specification

Stage 3: definition of requirement

Phase 4: logical system specification

Stage 4: technical system options

Stage 5: logical design

Phase 5: physical design

Stage 6: physical design

\subsection{Object-Oriented Methodologies}

By encapsulating processes and data together, defining objects, and capturing the essential building blocks of the system, Object-Oriented methodologies modularize the system, allowing objects to be defined based on boundaries existing in the real world system. Such methodologies encourage the analyst to look at the 'what' of a system rather than the 'how', holding off the design phase until all objects within the system have been analyzed to their fullest. This category encompasses such methodologies as: Rational Unified Process (RUP). (Kruchten, 2003)

The roots of rational processes go back to the original spiral model of Barry Boehm. The Rational Approach was developed at Rational Software in the 1980s and 1990s. The Rational Unified Process (RUP) is based on the integrated work of three primary methodologists, Ivar Jacobson, Grady Booch and, James Rumbaugh. The Unified Process is consists of cycles that may repeat over the long-term life of a system. A cycle is consists of four phases: Inception, Elaboration, Construction, and Transition. Each cycle is concluded with a release, there are also releases within a cycle. RUP is based on a set of building blocks, or content elements, describing what is to be produced, the necessary skills required and the step-by-step explanation describing how specific development goals are achieved. (Formal RUP, 2008)

The main building blocks, or content elements, are as follows:

Roles (who) - A Role defines a set of related skills, competences, and responsibilities.

Work Products (what) - A Work Product represents something resulting from a task, including all the documents and models produced while working through the process.

Tasks (how) - A Task describes a unit of work assigned to a Role that provides a meaningful result.

The process can be described in two dimensions, or along two axes: (Scott, 2005)

The horizontal axis represents time and shows the dynamic aspect of the process as it is enacted, and it is expressed in terms of cycles, phases, iterations, and milestones.

The vertical axis represents the static aspect of the process: how it is described in terms of activities, artifacts, workers and workflows.

\section{Soft Systems Methodologies in Information Systems Development}

These methodologies are focused on soft (human) aspect of systems and supposed that people in organisation are influenced in systems development process. We classify soft methodologies into two groups: ETHICS methodology and SSM.

\subsection{ETHICS Methodologies}

ETHICS is a shortened form of Effective Technical and Human Implementation of Computer- based Systems. The name of this method means methodology establishment which is designed by Enid Mumford. In order to make system effective, technology should have many adoptions with social and organisational factors. Therefore, the main goal of methodology from system design process is high quality of work life and extensive user job satisfaction. (Avison, 2006)

The steps of this methodology are as bellow: (Course of information systems development, 2005)

1) Why change? 2) System boundaries, 3) Description of existing system, 4, 5, and 6) Definition of key objectives and tasks, 7) Diagnosis of efficiency needs, 8) Diagnosis off job satisfaction needs, 9) Future analysis, 10) Specifying and weighing efficiency and job satisfaction needs, 11) The organisational design of the new system, 12) Technical options,

13) The preparation of a detailed work design, 14) Implementation, and 15) Evaluation.

\subsection{SSM Methodologies}

Checkland try to apply systems theory to an applicable methodology. He demonstrated that system analyzers apply their skills in problems which are not well-defined. These soft, fuzzy, or ill-structured problem situations which are 
complicated are ordinary in organisations. Checkland's methodology was developed in Lancaster University. He represented soft systems methodology description in 1981. SSM has seven stages which are shown in figure2.

Those stages which above dash line (1, 2, 5, 6 and 7 stages) are real world activities that contain people in problem situation. Those stages which below dash line ( 3 and 4 stages) are activities that think about problem situations. (Checkland \& Scholes, 1990)

\section{Existing Frameworks Deliberation for Hard and Soft Systems Methodologies Comparison}

There are different approaches for information systems development methodologies which we consider some of them:

\subsection{Andersen Framework}

Andersen identifies a checklist which includes criteria relating to values and society. This checklist is consists of the following questions:

1) What research paradigms/perspectives form the foundation for the methodology?

2) What are the underlying value systems?

3) What is the context where a methodology is useful?

4) To what extend is modification enhanced or even possible?

5) Does communication and documentation operate in the users' dialect, either expert or not?

6) Does transferability exist?

7) Is the societal environment dealt with, including the possible conflicts?

8) Is users participation really encouraged or supported?

This checklist is useful because focuses on those wider issues that are ignored. Furthermore, it's a subjective list and makes some assumptions. (Avison, 2006)

\subsection{NIMSAD Approach}

NIMSAD is the abbreviated of "Normative Information Model- based Systems Analysis and Design" and based on the models and epistemology of systems thinking and to a large degree evaluation and measures a methodology against these criteria. Three elements of this evaluation are:

The problem situation (the methodology context)

The intended problem solver (the methodology user)

The problem-solving process (the methodology)

The evaluation of elements has a wide-ranging and expressed in terms of the kinds of question that require answers. An example of questions which are related to the first elements is:

The clients and their understanding, experiences and problems.

A sample of questions concerning the second element is:

The methodology users' philosophical views, for example, science or systems-based.

A sample question concerning the third element asks about the way in which the methodology provides specific assistance for:

Understanding the situation of concern and setting of boundaries.

One feature of this framework is that it recommends that the evaluation be conducted at three stages. First, before intervention, second, during intervention, and finally, after intervention. These stages are important features of the framework and introduce the important element of organisational learning. (Avison, 2006)

\subsection{Avison and Taylor Approach}

Avison and Taylor identify five different classes of situation and appropriate approaches as follows: (Avison, 2006)

1) Well-structured problem situations with a well-defined problem and clear requirements. A traditional SDLC approach might be regarded as appropriate in this class of situation.

2) As above but with unclear requirements. A data, process modeling, or a prototyping approach is suggested as appropriate here.

3) Unstructured problem situation with unclear objectives. A soft systems approach would be appropriate in this situation.

4) High user-interaction systems. A people-focused approach, like ETHICS, would be appropriated here. 
5) Very unclear situations, where a contingency approach, such as multiview, is suggested.

\subsection{Presenting a Framework for Hard and Soft System's Methodologies Comparison}

As explained before, comparing methodologies is a very difficult task. There are different views as many as methodology writers. It is not necessary that analysts' views adopt on users views and in some cases are discordant. In this framework, we have six basic elements and some of them broken into some sub elements. The headings are not mutually exclusive and there are interrelationships between them. For example, aspects of philosophy are reflected in some senses. In the following section, we explain each of these elements:

\subsubsection{Philosophy}

We know the philosophy as a principle or set of principles that are background of methodology. The question of philosophy is an important aspect of methodology because choosing areas covering by methodology, orienting to people, data or systems, the bias or otherwise toward an IT solutions and other aspects are made on the base of methodology philosophy. Therefore it has influence on all other aspects. It may be explicit but in most methodologies, is implicit because methodology authors rarely stress on their philosophy. Philosophy consists of paradigm, objectives, domains, and applications.

\subsubsection{Model}

The second element of the framework concerns of analysis of the model that the methodology adhere to. The model is based on the view of methodology of the world. It is an abstraction and representation of important factors of the information systems or the organisation. Model is a means of communication. It is also a representation that provides insight into the problem or area of concern.

Models have four different types:

1) Verbal;

2) Analytic or mathematical;

3) Iconic, pictorial or schematic;

4) Simulations.

Models which concern with information systems methodologies are often of the third type.

\subsubsection{Tools}

A key element of the framework is the identification of tools used in a methodology.

\subsubsection{Scope}

Scope is an indication of the stages of the life cycle of systems development that methodology covers. Some methodologies do not follow a life cycle. They may adopt with an iterative, evolutionary or spiral model. Nevertheless, we suppose that an examination of methodology's scope in relation to the life cycle is useful.

\subsubsection{Background}

With this element, we can identify each methodology in which environment (academic or commercial) created.

\subsubsection{Participations}

It contains of users and analysts. Participations determine that can it be undertaken by users or must involved by professional analysts and what skills levels are required.

Table 1 compares introduced methodologies. In this table and in scope column, there signs are used:

$\square$ : Methodology covers this stage with its details.

冈: Methodology shows this area but with less details and practice.

口: It is introduced in methodology but no procedure, technique, or rule is provided.

\section{Conclusion}

The Proposed comparison framework is represented with attention to the key features of each methodology. These features play an important role in successful performing the methodologies. This represented framework can help organisations to select their suitable methodology based on methodology's features, to apply it in organisation, and to ensure that methodology will be performed successfully.

\section{Acknowledgement}

This study was supported by the institution of "Bonyad Melli Nokhbegan". Their contribution is gratefully acknowledged. 


\section{References}

Avison, D. \& Fitzgerald, G. (2006). Information Systems Development Methodologies, Techniques \& Tools, 4th Edition, McGraw Hill.

Checkland, P. B. (1981). Systems Thinking, Systems Practice. New York, Wiley.

Checkland, P.B. \& Scholes, J. (1990). Soft Systems Methodology in Action. John Wiley \& Sons, Chichester, UK.

Course information systems development, [Online] available: http://www.unl.ac.uk (May 12, 2008).

DehneRoel, F. \& Wieringa, J. (2003). The Yourdon Systems Method and the Toolkit for Conceptual Modeling, Faculty of Mathematics and Computer Science, March 20.

Formal RUP, [Online] available: http://www.rational.com (June 2, 2008).

Harry, M. (1997). Information Systems in Business. London, Pitman.

Inman, D. (2006). Course Business, Computing \& Information management, London South Bank University, [Online] available: http://www.bcim.lsbu.ac.uk/inmandw (July 10, 2008)

Kruchten, P. (2003). The Rational Unified Process: An Introduction, 3rd Edition, Dec 10, Addison Wesley Professional.

Niaki, A. (2001). Information Systems Creation and Development Methodologies Comparison, ISIran publication, Tehran, Iran.

Poon, K.H. (2005). SSADM - An Introduction, Office of the Government Chief Information officer.

Swindells, N. \& Moreno, A. (2005). Information Engineering - A New International Standard for the Long-term Archiving of Property Data. Ensuring Long-term Preservation and Adding Value to Scientific and Technical data (PV 2005), The Royal Society, Edinburgh, 21-23, November, 2005.

Scott, W. (2005). A Manager's Introduction to the Rational Unified Process (RUP), December 4, Ambysoft.

Watkins, J. (2003). Multi methodology: An Alternative Management Paradigm to Process Quality Improvement, Appendix C.

Yourdon Inc., (1993). Yourdon System method: Model-Driven Systems Development, Yourdon Press. 
Table 1. Methodology comparison and selection framework

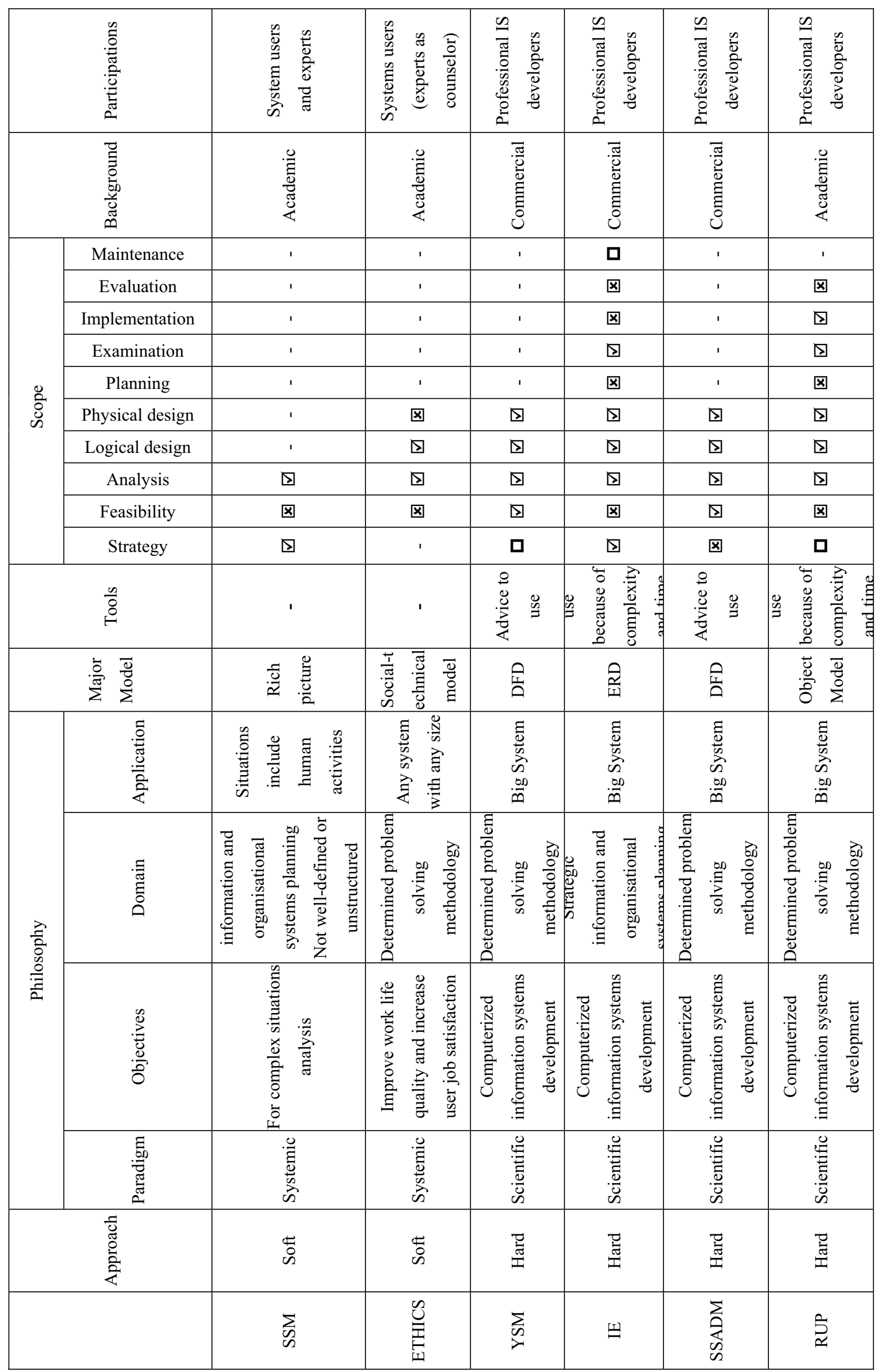




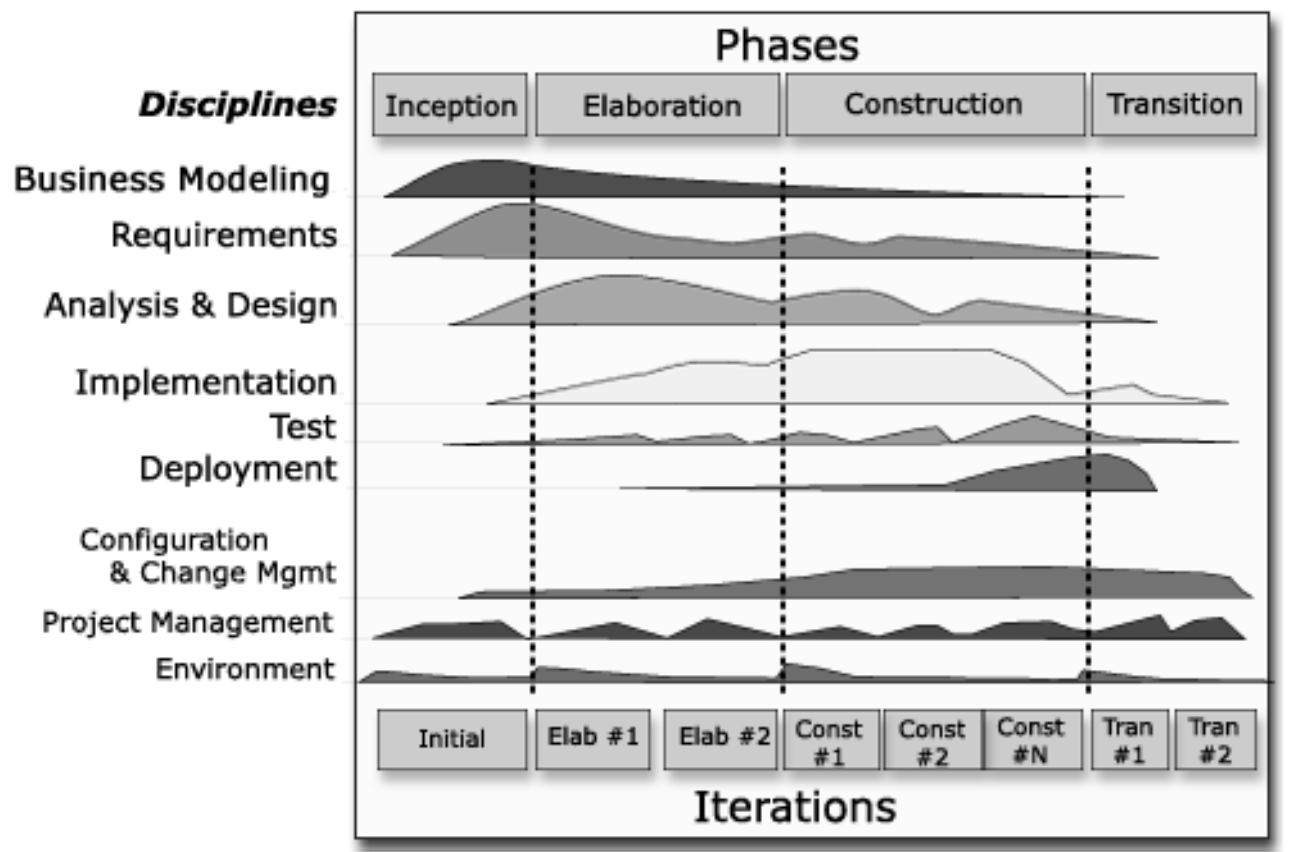

Figure 1. RUP General Structure (Scott, 2005)

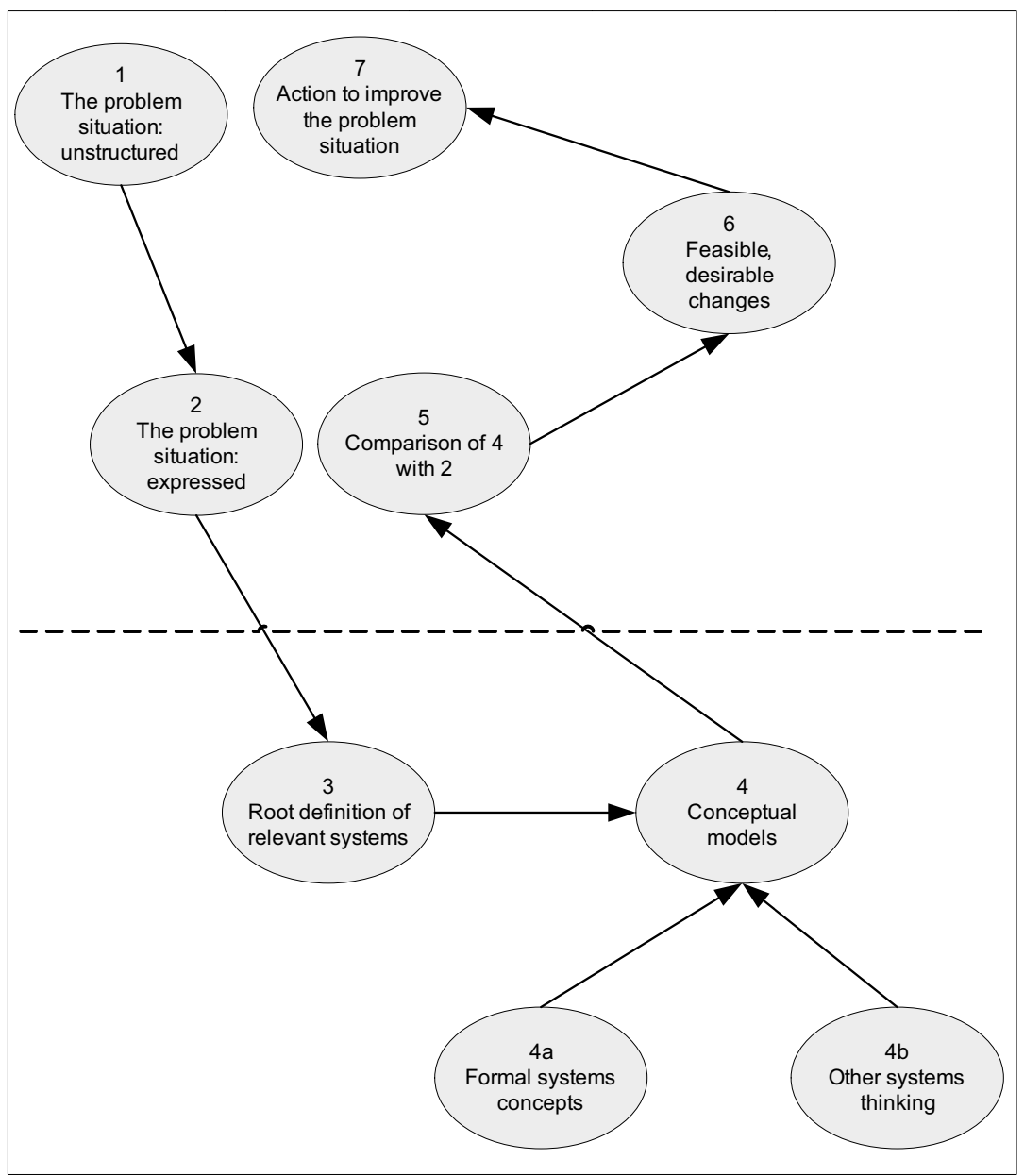

Figure 2. Soft Systems Methodology Stages (Checkland, 1981) 